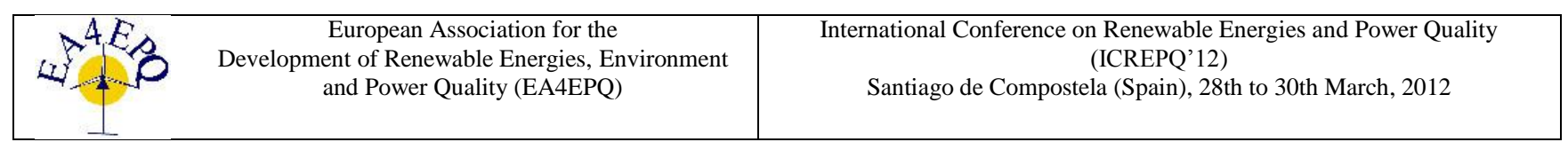

\title{
Evaluation of the Harmonic Impact in an Electrical System Using Polynomial- Regression Method
}

\author{
Thiago Mota Soares ${ }^{1}$ and Maria Emília de Lima Tostes ${ }^{2}$ \\ ${ }^{1}$ Universidade Federal do Pará \\ Rua Augusto Correa, no 1, Guamá, Belém-Brasil \\ thiago_motasoares@yahoo.com.br \\ ${ }^{2}$ Universidade Federal do Pará \\ Rua Augusto Correa, n 1, Guamá, Belém-Brasil \\ tostes@ufpa.br
}

\begin{abstract}
This paper presents a method to determine the individual harmonic influence of multiple harmonic-producing loads in an electrical power system. This method is based in the development of statistical models from measurement data using the polynomial-regression technique. A real case study is presented in order to show the performance of the proposed method.
\end{abstract}

\section{Key words}

Harmonic-producing loads, least-square method, Polynomial Regression, correlation factor.

\section{Introduction}

Determine the individual harmonic contribution of multiple harmonic-producing loads in an electrical power system is an important task for the management of the voltage harmonic distortion. However, due to the variety of harmonic sources present in electrical networks, it isn't an easy task to accomplish since the harmonic currents in power grids interact in such way as to cause increase or decrease of the harmonic distortion levels.

According to [1], there are two classes of methods to quantify the harmonic contribution of loads: the modelbased method and the data-based method. The modelbased method aims in the development of equivalent circuits to evaluate the impact of different harmonic sources. And the data-based method aims in the development of models from measurement data that describe the cause-effect relation of these data.

In [2], it was proposed a method based in the development of linear models from measurement data using linear regression techniques that describes the relation between the harmonic voltage in any point of an electrical system and the harmonic current of a harmonicproducing load.
This paper presents a method to determine the individual harmonic contribution of multiple harmonic-producing loads using the polynomial regression.

\section{Regression Analysis}

Regression analysis is a statistical method used to build models that describe the behaviour of a random variable (known as response or dependent variable) due to the variation of another variable or a set of variables, known as regressor or explanatory variables.

There are many methods for regression analysis where the simplest and the most common is the simple linear regression.

A more general form of the simple linear regression is the polynomial regression method since the regression model is represented by a $\mathrm{k}^{\text {th }}$-order polynomial equation instead of the first-order polynomial equation.

\section{A. Linear Regression}

A simple linear regression model is a regression model in which the regression equation is linear as shown in equations (1) and (2)

$$
\begin{gathered}
Y=\beta_{0}+\beta_{1} X+\epsilon \\
\epsilon \sim N\left(0 ; \sigma^{2}\right)
\end{gathered}
$$

where: $Y$ is the dependent variable

$X$ is the regressor

$\beta_{0}$ and $\beta_{1}$ are the linear model's coefficients $\epsilon$ is the error of the model

The linear model's coefficients are estimated through the least square method using the equations (3) and (4) 


$$
\begin{gathered}
\widehat{\beta_{0}}=\bar{y}+\widehat{\beta_{1}} \bar{x} \\
\widehat{\beta_{1}}=\frac{\sum_{i=1}^{n}\left(y_{i}-\bar{y}\right)\left(x_{i}-\bar{x}\right)}{\sum_{i=1}^{n}\left(x_{i}-\bar{x}\right)^{2}}
\end{gathered}
$$

\section{B. Polynomial Regression}

A polynomial regression model is a regression model in which the model is represented by a $\mathrm{k}^{\text {th }}$-order polynomial equation as shown in equations (5) and (6).

$$
\begin{gathered}
Y=\beta_{0}+\beta_{1} x+\cdots+\beta_{k} x^{k}+\epsilon \\
\epsilon \sim N\left(0 ; \sigma^{2}\right)
\end{gathered}
$$

In this model, $x$ is the fixed value of the regressor variable $X$, and the parameters $\beta_{0}, \beta_{1}$, and $\beta_{k}$ are the $\mathrm{k}^{\text {th }}$ polynomial coefficients, and $\boldsymbol{\epsilon}$ is the error of the model. According to [4], a polynomial regression method can cause an increasing in the flexibility of the relationship between the dependent variable and the regressor.

The least square method is used to estimate of the $\mathrm{k}^{\text {th }}$ order polynomial coefficients through equation (7).

$$
\hat{\beta}=\left(X^{\prime} X\right)^{-1} X^{\prime} y
$$

\section{Analysis of Variance}

Analysis of variance (ANOVA) is a method used to evaluate the significance of the regression model. This method is similar to hypothesis test where some inferences are made about the parameters of the population distribution.

According to [6], ANOVA decompose the total variability in the response variable into meaningful components as the basis of the test as shown in equation (8).

$$
\sum_{i=1}^{n}\left(y_{i}-\bar{y}\right)^{2}=\sum_{i=1}^{n}\left(y_{i}-\hat{y}_{i}\right)^{2}+\sum_{i=1}^{n}\left(\hat{y}_{i}-\bar{y}\right)^{2}
$$

The equation (8) can be rewritten as equation (9)

$$
S S_{T}=S S_{R}+S S_{E}
$$

where: $S S_{T}$ is the total corrected sum of squares, $S S_{R}$ is the regression sum of squares and $S S_{E}$ is the error sum of squares.

The value of the statistic $\left(F_{o}\right)$ can be calculated using the equation (10).

$$
F_{o}=\frac{S S_{R}}{S S_{E} /(n-2)}
$$

\section{Correlation Coefficient}

The correlation coefficient measures the possible linear relation that might exist between two random variables. Its value lies between -1 and 1 . The equation (8) is used to calculate the correlation coefficient.

$$
\rho(X, Y)=\frac{\operatorname{Cov}[X, Y]}{\sqrt{\sigma_{x}^{2} \sigma_{y}^{2}}}
$$

Where $\operatorname{Cov}[X, Y]$ is the covariance between variables $\mathrm{X}$ and $\mathrm{Y}$, and $\sigma_{x}^{2}$ and $\sigma_{y}^{2}$ are the variance of $\mathrm{X}$ and $\mathrm{Y}$ variance, respectively.

\section{E. The Coefficient of Determination $\left(R^{2}\right)$}

The coefficient of determination (also known of $R^{2}$ coefficient) is a measure of the model fitting obtained by a regression analysis. It is calculated by (12), and as its value closer to 1 , better is the model fitting.

$$
R^{2}=\frac{S S_{R}}{S S_{T}}
$$

Where $\mathrm{SS}_{\mathrm{T}}$ represent the total variation of $\mathrm{Y}$ around its average, and $\mathrm{SS}_{\mathrm{R}}$ represent the variation of $\mathrm{Y}$ 's expected value around its average.

\section{Methodology}

To determine the contribution of multiple harmonicproducing loads scattered in an electrical network, this paper proposes to create data-based models that describe the influence of harmonic currents produced by nonlinear loads on the voltage harmonic distortion using the polynomial regression method.

\section{Case Study}

In this section, it is presented a study performed in a real electrical system located in the north of Brazil. In this system, it was noticed the presence of two dominant harmonic-producing loads called FH1 and FH2. This system's diagram is shown in Fig 1.

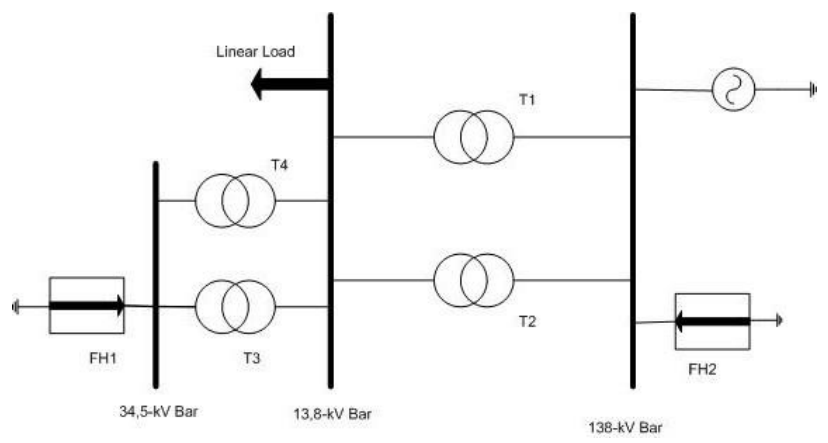

Fig. 1. Electrical diagram of the system

A measurement campaign was conducted in this system and revealed the presence of high levels of voltage and current harmonic distortion, mainly $3^{\text {rd }}$ and $5^{\text {th }}$ harmonics. The power-quality analyzers were installed in two sites: $\mathrm{FH} 1$ and $\mathrm{FH} 2$ in order to estimate how these harmonic sources influence the harmonic levels in bars of $34.5 \mathrm{kV}$ and $138 \mathrm{kV}$. In Fig 2 and Fig 3 are shown the voltageand-current trend of the $3^{\text {rd }}$ and $5^{\text {th }}$ harmonics measured at source FH1, respectively. 
Applying the polynomial regression method to these measurement data, it was obtained the graphics shown in Fig 4 and Fig 5, that describe the voltage-current relationship for $3^{\text {rd }}$ and $5^{\text {th }}$ harmonics, respectively.

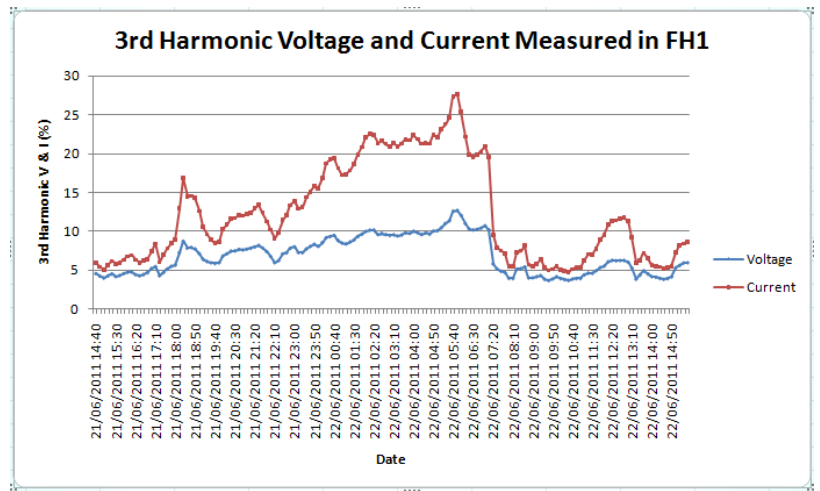

Fig. 2. Graphic of $3^{\text {rd }}$-harmonic Voltage measured in $34.5 \mathrm{kV}$ bar and $3^{\text {rd }}$-harmonic current measured in FH1

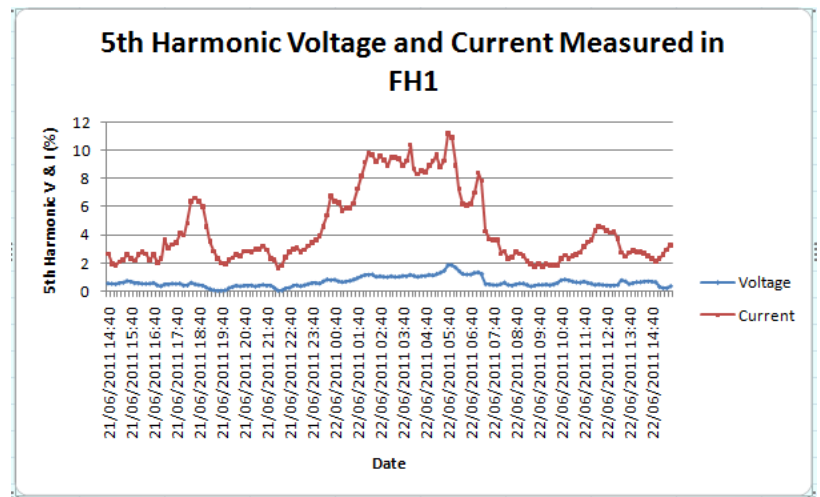

Fig. 3. Graphic of $5^{\text {th }}$-harmonic Voltage measured in $34.5 \mathrm{kV}$ bar and $5^{\text {th }}$-harmonic current measured in FH1

According to Fig 4, the statistical model that describes the voltage-current relationship for the $3^{\text {rd }}$ harmonic is the $2^{\text {nd }}$-order polynomial equation shown in equation (13).

$$
V_{3}=1.417+0.536 I_{3}-0.005939 I_{3}^{2}
$$

This regression equation was selected due to its high significance since its F-statistic values were high as shown in table I. In addition, the coefficient of determination of this model was 0.97 which means that the model perfectly fitted to the data.

Table I. F-Statistics values of the $2^{\text {th }}$-order polynomial model (13)

\begin{tabular}{|c|c|}
\hline Explanatory Variables & F Values \\
\hline$I_{3}$ & 5653.83 \\
\hline$I_{3}^{2}$ & 38.71 \\
\hline
\end{tabular}

The equation (13) suggests that the harmonic source FH1 is responsible for $80.96 \%$ of the $3^{\text {rd }}$-harmonic voltage distortion in the $34.5 \mathrm{kV}$ bar. And, if there wasn't $3^{\text {rd }}$ harmonic current being absorbed or injected into the system by $\mathrm{FH} 1$, the $3^{\text {rd }}$-harmonic voltage in the $34.5 \mathrm{kV}$ bar would be approximately $1.425 \%$.
Impact of FH1 on the 3rd Harmonic voltage of the $34.5 \mathrm{kV}$ Bar

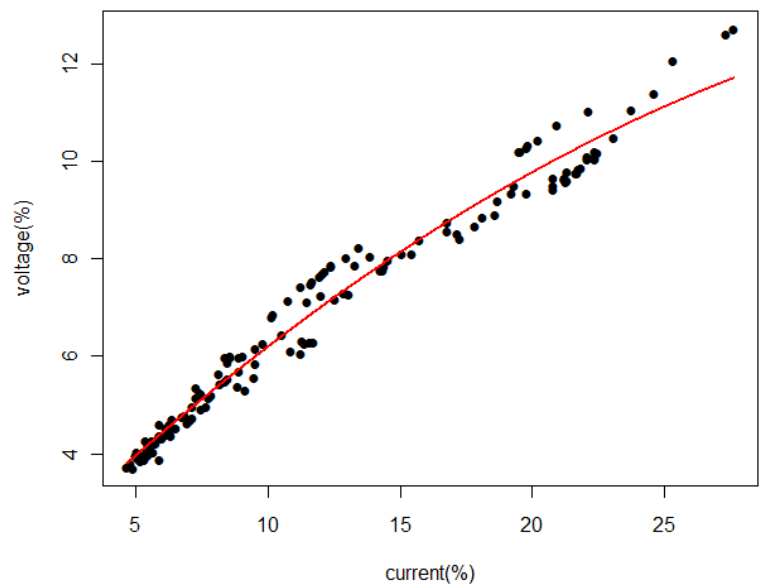

Fig 4. Correlation between the $3^{\text {rd }}$-harmonic Current FH1 and voltage of $34.5 \mathrm{kV}$ bar

To analyze the influence of the harmonic source FH1 on the $5^{\text {th }}$-harmonic voltage distortion of the $34.5 \mathrm{kV}$ bar, it was built the statistical model shown in Fig 4 that is represented by the $1^{\text {rst }}$-order polynomial equation shown in equation (14).

$$
V_{5}=0.1883+0.1091 I_{5}
$$

The regression equation (14) was the equation that presented the highest significance since its F-statistic value was 383.91. In addition, this model's coefficient of determination was 0.67 which means that the model fitted reasonably well to the measurement data.

The equation (14) suggests that the harmonic source FH1 is responsible for $65.64 \%$ of the $5^{\text {th }}$-harmonic voltage distortion in the $34.5 \mathrm{kV}$ bar. And, if there wasn't $5^{\text {th }}$ harmonic current being absorbed or injected by FH1 into the system, the $5^{\text {th }}$-harmonic voltage in the $34.5 \mathrm{kV}$ bar would be approximately $0.1883 \%$.

Impact of FH1 on the 5th Harmonic voltage of the $34.5 \mathrm{kV}$ B

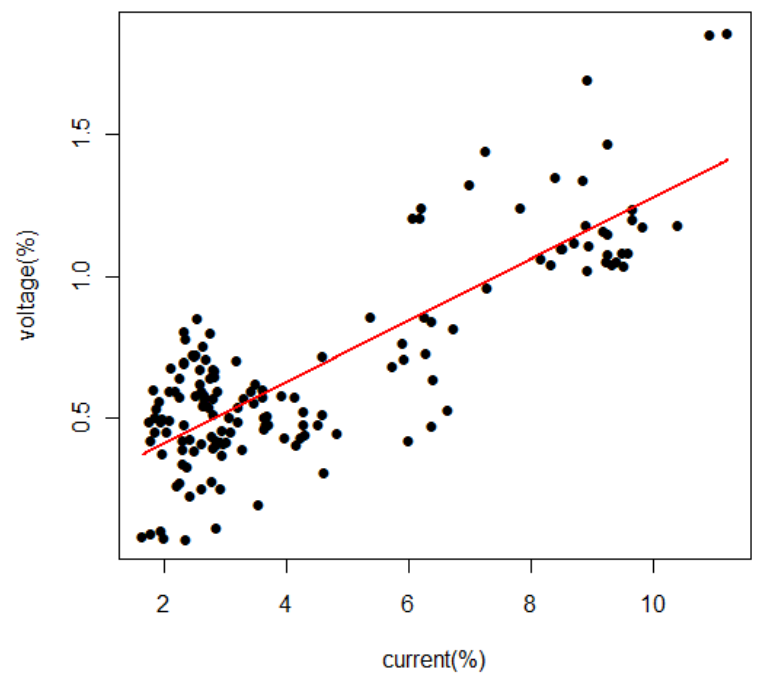

Fig 5. Correlation between the $5^{\text {th }}$-harmonic Current FH1 and voltage of $34.5 \mathrm{kV}$ bar 
In Fig 6 and Fig 7 are shown the voltage-and-current trend of the $3^{\text {rd }}$ and $5^{\text {th }}$ harmonics measured at source $\mathrm{FH} 2$, respectively.

Applying the polynomial regression method to these measurements, it was obtained the graphics shown in Fig 8 and Fig 9, that describe the voltage-current relationship for $3^{\text {rd }}$ and $5^{\text {th }}$ harmonics at $\mathrm{FH} 2$, respectively.

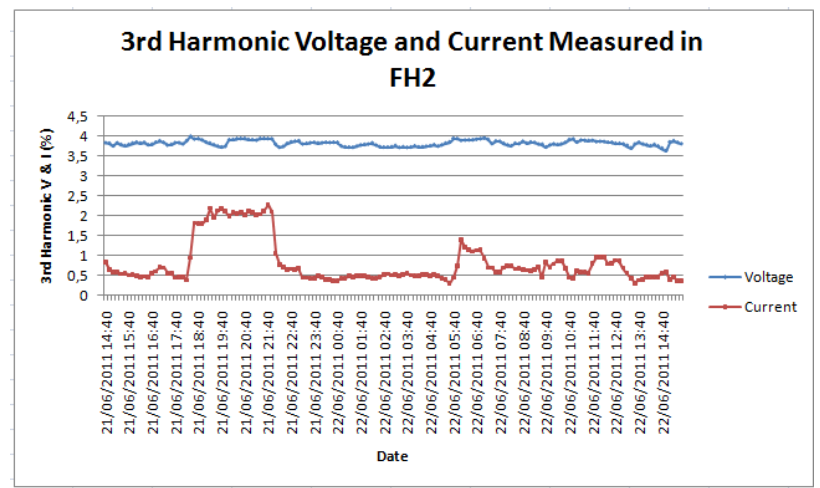

Fig. 6. Graphic of $3^{\text {rd }}$ Harmonic Voltage and Current Measured in $\mathrm{FH} 2$

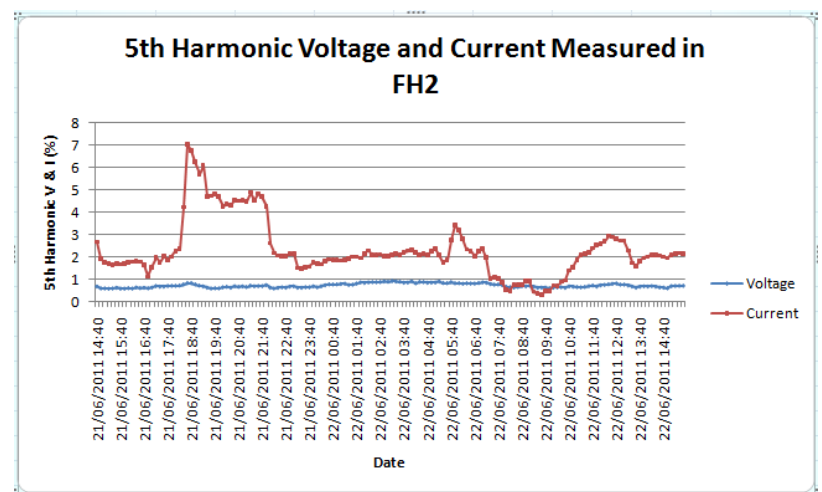

Fig. 7. Graphic of $5^{\text {th }}$ Harmonic Voltage and Current Measured in $\mathrm{FH} 2$

To analyze the influence of the harmonic source $\mathrm{FH} 2$ on the $3^{\text {rd }}$-harmonic voltage distortion of the $138 \mathrm{kV}$ bar, it was built the statistical model shown in Fig 8 that is represented by the $4^{\text {th }}$-order polynomial equation shown in equation (15).

$$
V_{3}=4.15-1.64 I_{3}+2.43 I_{3}^{2}-1.3 I_{3}^{3}+0.23 I_{3}^{4}
$$

The regression equation (15) presented higher significance than the other equations since its F-statistic values shown in table II were higher than the other equation's values. In addition, the coefficient of determination of this model was 0.25 which means that the model poorly fit to the data.

Table II. F-Statistics values of the $4^{\text {th }}$-order polynomial model

\begin{tabular}{|c|c|}
\multicolumn{2}{|c|}{$(15)$} \\
\hline Explanatory Variables & F-statistic Values \\
\hline$I_{3}$ & 36.13 \\
\hline$I_{3}^{2}$ & 4.44 \\
\hline$I_{3}^{3}$ & 7.73 \\
\hline$I_{3}^{4}$ & 5.87 \\
\hline
\end{tabular}

The equation (15) suggests that the harmonic source FH2 is responsible for $-7.25 \%$ of the $3^{\text {rd }}$-harmonic voltage distortion in the $138 \mathrm{kV}$ bar. And, if there wasn't $3^{\text {rd }}$ harmonic current being absorbed or injected into the system by $\mathrm{FH} 2$, the $3^{\text {rd }}$-harmonic voltage in the $138 \mathrm{kV}$ bar would be approximately $4.15 \%$.

Impact of FH2 on the 3rd Harmonic voltage of the 138kV Bar

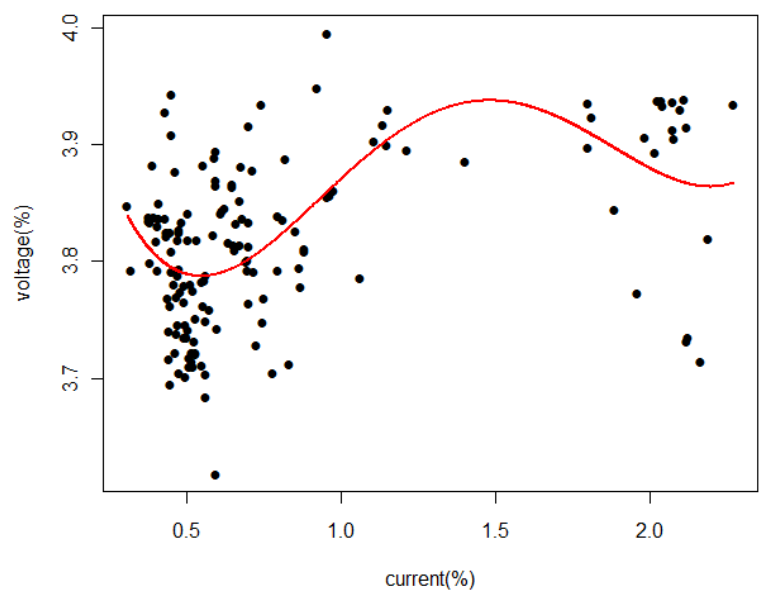

Fig 8. Correlation between the $3^{\text {rd }}$-harmonic Current FH2 and voltage of $138 \mathrm{kV}$ bar

To analyze the influence of the harmonic source $\mathrm{FH} 2$ on the $5^{\text {th }}$-harmonic voltage distortion of the $138 \mathrm{kV}$ bar, it was built the statistical model shown in Fig 9 that is represented by the $5^{\text {th }}$-order polynomial equation shown in equation (16).

$$
V_{5}=0.858-0.566 I_{5}+0.52 I_{5}^{2}-0.174 I_{5}^{3}+0.024 I_{5}^{4}-0.001 I_{5}^{5}
$$

The regression equation (16) presented higher significance than the other equations since its F-statistic values shown in table III were higher than the other equation's values. In addition, the coefficient of determination of this model was 0.22 which means that the model poorly fitted to the data.

Table III. F-Statistics values of the $5^{\text {th }}$-order polynomial model

\begin{tabular}{|c|c|}
\hline \multicolumn{2}{|c|}{$(16)$} \\
\hline Explanatory Variables & F-statistic Values \\
\hline$I_{5}$ & 2.889 \\
\hline$I_{5}^{2}$ & 8.82 \\
\hline$I_{5}^{3}$ & 17.71 \\
\hline$I_{5}^{4}$ & 12.24 \\
\hline$I_{5}^{5}$ & 5.03 \\
\hline
\end{tabular}

The equation (16) suggests that the harmonic source FH2 is responsible for $9.55 \%$ of the $5^{\text {th }}$-harmonic voltage distortion in the $138 \mathrm{kV}$ bar. And, if there wasn't $5^{\text {th }}$ harmonic current being absorbed or injected by FH2 into the system, the $5^{\text {th }}$-harmonic voltage in the $138 \mathrm{kV}$ bar would be approximately $0.858 \%$. 


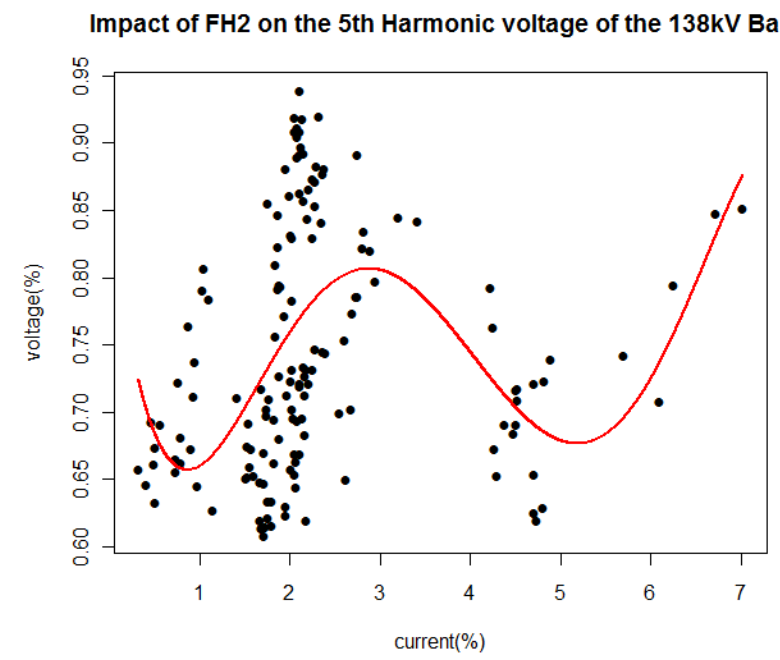

Fig 9. Correlation between the $5^{\text {th }}$-harmonic Current of FH2 and voltage of $138 \mathrm{kV}$ bar

To analyze the influence of the harmonic source FH1 on the $3^{\text {rd }}$-harmonic and $5^{\text {th }}$-harmonic voltage distortion of the $138 \mathrm{kV}$ bar, it were built the statistical models shown in Fig 10 and Fig 11, respectively, that were represented by the $3^{\text {rd }}$-order and $2^{\text {nd }}$-order polynomial equations shown in equation (17) and (18), respectively.

$$
\begin{gathered}
V_{3}=3.47+0.086 I_{3}-0.006 I_{3}^{2}+0.0001 I_{3}^{3} \\
V_{5}=0.53+0.064 I_{5}-0.0028 I_{5}^{2}
\end{gathered}
$$

The regression equations (17) and (18) presented higher significance than the other equations since their Fstatistic values shown in tables $\mathrm{V}$ and VI, respectively, and were higher than the other equation's values. In addition, the coefficient of determination of the $3^{\text {rd }}$-order and $2^{\text {nd }}$-order polynomial models were 0.16 and 0.88 , respectively, which means that the $3^{\text {rd }}$-order model poorly fitted to the data and $2^{\text {rd }}$-order model fitted well to the data.

Table V. F-Statistics values of the $3^{\text {rd }}$-order polynomial model

\begin{tabular}{|c|c|}
\multicolumn{2}{c}{$(17)$} \\
\hline Explanatory Variables & F-statistic Values \\
\hline$I_{3}$ & 0.02 \\
\hline$I_{3}^{2}$ & 7.49 \\
\hline$I_{3}^{3}$ & 24.76 \\
\hline
\end{tabular}

Table VI. F-Statistics values of the $2^{\text {nd }}$-order polynomial model (18)

\begin{tabular}{|c|c|}
\hline Explanatory Variables & F-statistic Values \\
\hline$I_{5}$ & 0.02 \\
\hline$I_{5}^{2}$ & 7.49 \\
\hline
\end{tabular}

The equation (17) and (18) suggest that the harmonic source FH1 is responsible for $4.0 \%$ and $38.87 \%$, respectively, of the $3^{\text {rd }}$-order and $5^{\text {th }}$-harmonic voltage distortion in the $138 \mathrm{kV}$ bar. And, if there wasn't $3^{\text {rd }}$-order and $5^{\text {th }}$-harmonic currents being absorbed or injected into the system by $\mathrm{FH} 1$, the $3^{\text {rd }}$-harmonic and $5^{\text {th }}$-harmonic voltage in the $138 \mathrm{kV}$ bar would be approximately $3.47 \%$ and $0.53 \%$, respectively.
Impact of FH1 on the 3rd Harmonic voltage of the 138kV Bar

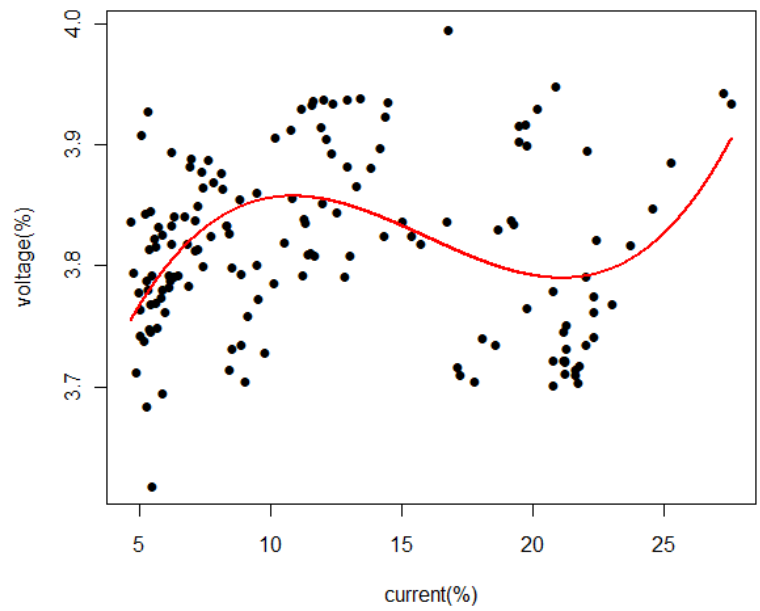

Fig 10. Correlation between the $3^{\text {rd }}$-harmonic Current of FH1 and voltage of $138 \mathrm{kV}$ bar

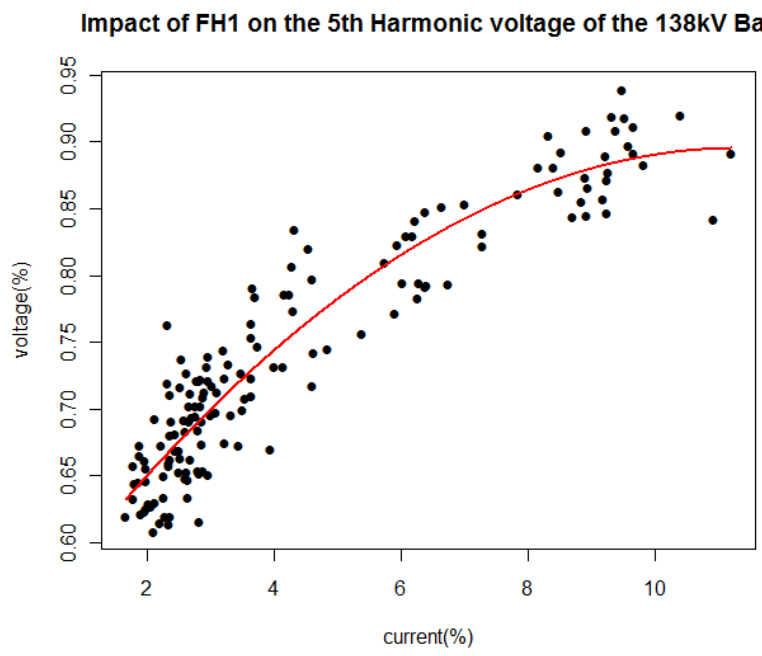

Fig 10. Correlation between the $5^{\text {th }}$-harmonic current of FH1 and voltage of $138 \mathrm{kV}$ bar

To analyze the influence of the harmonic source $\mathrm{FH} 2$ on the $3^{\text {rd }}$-harmonic and $5^{\text {th }}$-harmonic voltage distortion of the $34.5 \mathrm{kV}$ bar, it were built the statistical models shown in Fig 12 and Fig 13, respectively, that were represented by the $3^{\text {th }}$-order and $2^{\text {nd }}$-order polynomial equations shown in equation (19) and (20), respectively.

$$
\begin{gathered}
V_{3}=14.84-27.94 I_{3}+27.41 I_{3}^{2}-7.54 I_{3}^{3} \\
V_{5}=0.42+0.24 I_{5}-0.045 I_{5}^{2}
\end{gathered}
$$

The regression equations (19) and (20) presented higher significance than the other equations since their Fstatistic values shown in tables VII and VIII, respectively, and were higher than the other equation's values. In addition, the coefficient of determination of the $3^{\text {th }}$-order and $2^{\text {nd }}$-order polynomial models were 0.01 and 0.11 , respectively, which means that both $3^{\text {th }}$-order $2^{\text {rd }}$-order models poorly fitted to the data. 
Table VII. F-Statistics values of the $3^{\text {th }}$-order polynomial model

\begin{tabular}{|c|c|}
\hline \multicolumn{2}{|c|}{$(19)$} \\
\hline Explanatory Variables & F-statistic Values \\
\hline$I_{3}$ & 1.0074 \\
\hline$I_{3}^{2}$ & 0.78 \\
\hline$I_{3}^{3}$ & 14.22 \\
\hline
\end{tabular}

Table VIII. F-Statistics values of the $2^{\text {nd }}$-order polynomial

\begin{tabular}{|c|c|}
\multicolumn{2}{|c|}{ model $(20)$} \\
\hline Explanatory Variables & F-statistic Values \\
\hline$I_{5}$ & 5.09 \\
\hline$I_{5}^{2}$ & 15.44 \\
\hline
\end{tabular}

The equation (19) and (20) suggest that the harmonic source $\mathrm{FH} 2$ is responsible for $-82.26 \%$ and $17.94 \%$, respectively, of the $3^{\text {rd }}$-order and $5^{\text {th }}$-harmonic voltage distortion in the $34.5 \mathrm{kV}$ bar. And, if there wasn't $3^{\text {rd }}$ order and $5^{\text {th }}$-harmonic currents being absorbed or injected into the system by $\mathrm{FH} 1$, the $3^{\text {rd }}$-harmonic and $5^{\text {th }}$-harmonic voltage in the $138 \mathrm{kV}$ bar would be approximately $14.84 \%$ and $0.42 \%$.

Impact of FH2 on the 3rd Harmonic voltage of the $34.5 \mathrm{kV}$ Bar

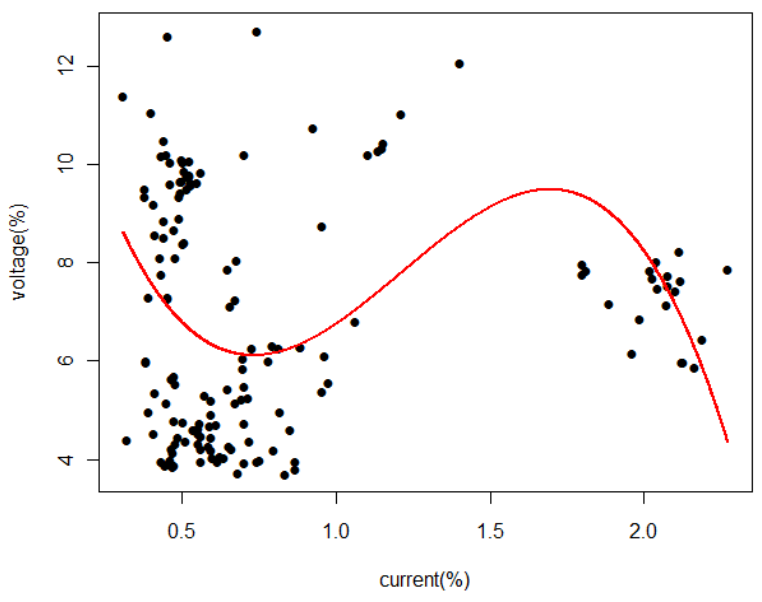

Fig 11. Correlation between the $3^{\text {rd }}$-harmonic Current of FH2 and voltage of $34.5 \mathrm{kV}$ bar

Impact of $\mathrm{FH} 2$ on the 5 th Harmonic voltage of the $34.5 \mathrm{kV}$ Bar

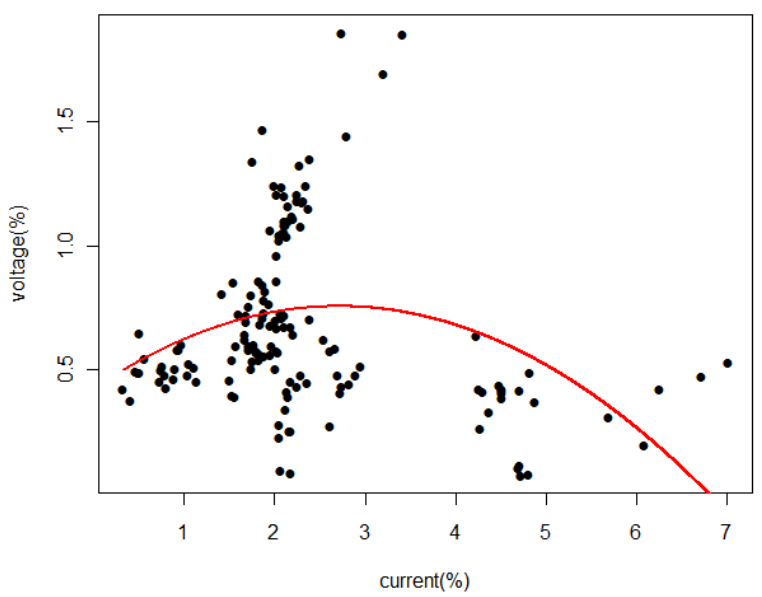

Fig 12. Correlation between the $5^{\text {th }}$-harmonic Current of FH2 and voltage of $34.5 \mathrm{kV}$ bar

\section{Conclusion}

This paper developed statistical models using the polynomial regression method that described the relationship between the harmonic voltage and current of an electrical system located in the north of Brazil.

Some of the models presented a satisfactory performance and significance and were able to describe the influence of some harmonic sources in the harmonic voltage level of this system.

In this study, the harmonic source FH1 presented a high influence on the levels of voltage harmonic distortion in the studied sites of the system.

\section{Acknowledgement}

This work has been supported by CAPES.

\section{References}

[1] H. E. Mazin, W. Xu and B. Huang, "Determining the Harmonic Impacts of Multiple Harmonic-Producing Loads", IEEE Trans. On Power Delivery, Vol 26, NO. 2, April, 2011.

[2] W. Xu, R. Bahry and H. E. Mazin, "A Method to determine the Harmoni Contributions of Multiple Loads", Power \& Energy Society General Meeting, 2009.

[3] J. O. Rawllings, S. G. Pantula and D. A. Dickey, Applied Regression Analysis: A Research Tool. Springer (1998).

[4] R. Charnet, C. Freire, E. Charnet and H. Bonvino. Análise de Modelos de Regressão Linear com Aplicações. Editora Unicamp. 2008

[5] Xin Yan, and Xiao Gang Su. Linear Regression Analysis: Theory and Practice. World Scientific. 2009

[6] Douglas C. Montgomery and George C. Runger. Applied Statistics and Probability for Engineers. John Wiley \& Sons. 2002 